\title{
Satisfaction and Professional Mobility: A Franco-Argentine Study About PhD, in the Light of a Sui Generis Paradigm
}

\section{Miriam Aparicio $^{a}$}

\begin{abstract}
The research dealt with PhD graduates who had obtained their degrees from 2005 onwards and PhD students from different courses of study belonging to Cuyo University (UNCuyo, Argentina) and CNAM (France). The purpose was to analyze the relation between professional mobility and professional satisfaction, variables hard to reach a competitive and uncertain work world and within education institutions which do not always train adequately in the competences required by the market. Associated to them, we analyzed the professionalization factor and the identity strategies involved in confronting the problems at work. The methodology used was quantitative (statistical analysis) but mainly qualitative (interviews and hierarchical evocations). This technique shows which aspects enter into the focus of the representations of the doctors regarding the relation of education/work and of the conditioning factors of achievement, and which aspects are "peripheral". The analysis was carried out from Dr. Aparicio's approach-The Theory of Three Dimensional Spiral of Sense-i.e., in the light of three-level interplay: micro, meso, and macro levels. Also, we took as reference the "Expectancy-Valence Theory" and the Theory of Education as "Consumption or Investment". The results show non-linear but spiral (in feedback) relations between the variables of the model (psycho-social, organizational, and structural factors) according to disciplinary fields and national contexts.
\end{abstract}

\section{Keywords}

PhD graduates, social representations, professional mobility, satisfaction, identity

This study is part of a set of continuous works concerning professional performance and its connection with the employment market of different populations (university graduates, drop-outs, and students who take longer to complete their studies, teachers, scientists, etc.), covering 20 years of existence of different courses of study at Universidad Nacional de Cuyo (UNCuyo, Argentina). The social (shared) representations of Social and Humanistic Sciences doctors/Ph.D. students from UNCuyo are compared with those who receive populations of similar characteristics and have studied courses in the same professional fields at CNAM (National Conservatory of Arts and Crafts, Paris, France). The core issue of this study lies in the analysis of professional mobility in relation with the field of training, on the one hand, and with professional satisfaction, on the other.

\footnotetext{
aNational University of Cuyo, Mendoza, Argentina

Correspondent Author:

Miriam Aparicio, Paso de los Andes 983, Ciudad, Mendoza (5500), Argentina
} 


\section{OBJECTIVES}

(1) Being aware of the relation between the level of satisfaction and professional mobility in the groups of French and Argentine doctors according to disciplinary fields and expectations, within a context of degree devaluation and the "plafond" effects (graduates saturation/higher education overspreading).

(2) Understanding the interplay among the micro-psychological, meso institutional/organizational, and macro (social, economic, and political) regarding education and work, as from the representations shared by both groups of doctors (French and Argentine).

(3) Providing those in charge of the educational sector (French and Argentine) with material for reflection in order to implement programs aiming at improving the quality of continuous training and, therefore, labor insertion.

\section{CORE QUESTIONS OF THIS RESEARCH}

How and where are the doctors in education and social sciences positioned within the market? What is their professional status? Did they become aware of professional mobility the moment they started their $\mathrm{Ph}$.D. education? In case they have reached relatively high positions in the job hierarchy, do they associate such mobility (status) to the expected satisfaction? Are the most satisfied individuals those with the best positions? Which factors are associated to their level of satisfaction? Are these material factors (salary, for example) or human factors [occupational climate, atmosphere at work, interaction between the different hierarchical levels, their feeling of being competent for the new position's demands, and the possibility for upgrading (or updating)] in their places of employment? Which value is better ranked: money and economic development or a pleasant working environment, according to their calling, even if they may "sacrifice" a better income? Do they view Ph.D. training as investment or "consumption", according to the Consumption-Investment theories (Mingat and Rasera 1981; Becker 1964)? What role does superiors' and inferiors' recognition play? Do they consider that, in view of the present work market situation, people appreciate the expected "extra" rather than a doctor in material of innovation? Which prevails in the national groups, hope or pessimism? Finally, do these doctors (French and Argentine) share specific "identities" and "interests"? What are their differences and similarities?

\section{THEORETICAL FRAMEWORK}

Let us carry out the analysis dealing with different aspects which we consider essential for the interpretation of results.

\section{The Training/Market Relationship}

Firstly, we could think that a higher level of professional mobility corresponds with a higher level of professional satisfaction and wellbeing. However, as we will alter outline, findings show non-linear relationships. As for the rest, this aspect is associated to identity. As other recent articles have pointed out (Aparicio 2014b; 2015a; 2015b; 2015c; 2016a; 2016b; 2016c; Silva and Aparicio 2015), doctors' present situation, which is different as regards disciplinary area and country, is far from the situation a few years ago. On the one hand, the "plafond" effect, or saturation of graduates, has an impact not only on occupational promotion or mobility but also on insertion itself (the Queuing Theory, García Rodríguez 1993; Lévy-Garboua 1976; Boudon 1973). From a subjective facet, such saturation, associated to higher education overspreading, has an impact on professional satisfaction and on professional identities. These identities, as some complementary studies show, would quite often appear segmented or weakened in a globalized and competitive world which not always provides the conditions for professional fulfillment, from the training level as well as from the market itself. 
Taking training into consideration, focalizing on "knowing what" (disciplinary aspects) does not seem consistent with what the market values most at the time for recruiting [also, "knowing how", or procedural aspects, and "knowing how to be" (knowing how to live with others)]. In fact, training in social competences (leadership, communication, cooperation, teamwork, problem solving, and healthy interactions), as well as management and decision-making competences (meta-competences), is often left aside as a marginal aspect. They, in turn, influence other cross-competences (critical thinking ability, Argyris and Schön 1978; 1996). Also, continuing, or permanent, or "lifelong" education, often talked about, particularly in less developed countries, has not reached yet the required organizational and systematization capacities to be able to train in the abilities today's market demands (Aparicio 2015a; 2015b; 2015c; 2016a; 2016c; 2016d; Bourdoncle and Demailly 1998; Ozga and Lawn 1981). Professionalization is fundamental when there are abrupt changes which demand adaptability. The lack of professionalization at the expected levels places individuals in an unfavorable situation with regard to new scenarios and also affects their identity. It goes without saying that professional identity is a construct emerging from the combination of the biographical aspect (previous history/career) and the relational aspect. Here appears the problem of the other's recognition: from staff recruiters, from evaluators, and from those who determine if the individual has or does not have professional mobility. There also appears the power of socialization, since evaluators (broadly speaking) as well as the individuals internalize the socio-cultural rules denoting what it is or is not valued according to different contexts.

From the point of view of the market, the issue is complex and different according to the different countries: "delocalization", accompanied by job loss, is growing in developed countries. The work climate/atmosphere reveals other issues, or makes them more evident (harassment, discrimination, and rejection from the other or "different one"). These issues seemed diluted within political discourses and platforms which hardly ever leave aside the matters of diversity, inclusion, and integration. In addition, we should mention the required alignment, yet "covered" by the need to protect "the identity and subsistence of the business". This causes a slit between what is expected and the conditions of practice in day-to-day work (Goffman 1963), between the "ideal" situation expected by the Ph.D. students and the real one of the Ph.D. graduates. However, the gap between education and work looks more obvious according to countries and disciplinary fields, becoming more difficult to rise in the professional rank in areas such as education, where rising often depends on hierarchy, seniority, "quotas", and related aspects, and still disregarding competences as core factors (public sector). Mobility is quite limited, unlike the area of business management, where mobility is higher and, therefore, achieving a hierarchical status is quite probable (private sector).

Within this framework, the links between the personal training experience and the professional life become a source of concern in the field of training and, especially, in the studies related to humanities and social sciences.

Notwithstanding this issue, doctors, in general, still considers that reaching such level of education represents an "extra" in relation with the work market (this becomes more evident in Argentina than in France where saturation is higher and lack of recognition appears as the main negative factor).

\section{The Professional \\ Mobility/Satisfaction/Expectations Relationship}

This relationship was another issue to analyze. Unsurprisingly, we noticed that there was not a direct relationship, which led to the coinage of the term 
subjective satisfaction to refer to experienced satisfaction, and objective satisfaction (which accompanies the recognition underlying rise) (Aparicio 2016e; 2016f).

Expectations, within the framework of the interviews, also appear playing a central role: If the context of professional practice does not come close to what is expected, then "lived" satisfaction is low. Conversely, teaching jobs, with low income and prestige (especially, in the context of degrees devaluation), reach a considerable level of satisfaction. The Expectancy-Valence Theory (Feather and Davenport 1981) as well as the Queuing Theory (García Rodríguez 1993) and the "Consumption-Investment" Theory (Mingat and Rasera 1981) play a very important role.

\section{METHODOLOGY}

The quantitative-qualitative method was applied. This study refered only to the qualitative method.

Our theoretical model includes, at least, the five variable types (core, psychosocial, pedagogical-institutional, organizational, and structural variables). These variables, according to our sui generis systemic approach, interact within a "self-sustained" movement (feedback). This approach joins explanation and comprehension. As strategies, the macro-meso-micro-macro dimensions are gathered: processes and results; transversal and quasi-longitudinal (personal experiences or life, ...); diachronically and synchronically. Besides, analyzing the actual actors' representations helps us work not only at the quantitative level (explanatory, with inputs and outputs), but also, and fundamentally, with the "human processes" that appear on the base, showing "reasons" conditioning and making "sense" of such achievement.

\section{Participants}

Consisting of doctors in Education and Social Sciences at Universidad Nacional de Cuyo (UNCuyo)
(2005-2009), and doctors under training in Adult Education, Sociology, and Gestion (Administration) at CNAM (National Conservatory of Arts and Crafts) (France). Two research laboratories took part in this work. It is expected to find different profiles according to the work/professional contexts in which they are situated.

\section{Materials}

Quantitative and qualitative techniques were applied ("hierarchical evocation" and the lexicometric analysis techniques). The latter allowed us to show which representations are part of the "nucleus" of a Ph.D. training in each of the national groups, and which are their most evident differences in term of professional mobility associated to having obtained a $\mathrm{Ph}$.D. degree, satisfaction in professional identity.

\section{RESULTS}

The results are presented according to certain core issues.

(1) The market and the possibilities it offers in different professional fields: There is a marked difference regarding the most favored values according to the disciplinary area the doctors studied and their views of future perspectives in the work market. The micro-individual relation (rooted in the psychology of the individual) and the meso-institutional (university) or organizational (market) facet appear evident. Considering our theory-the Three-Dimensional Spiral of Sense (Aparicio 2015a; 2015b), there is an obvious interplay that becomes. In fact, doctors belonging to the fields of sociology and similar areas in both countries valued the market more negatively, as can be observed by the words they expressed most recurrently and to which they gave most importance (Aparicio and Cros 2015; Aparicio 2016e; 2016f). It would seem that many more factors associated to worries, beliefs, and ideology, are filtered into their representations 
(particularly, liberalism, which is much more rejected in the French rather than in the Argentine context). In the field of education, the differences appear, especially, at the time of assessing competences (always according to recurrence and importance). Within the French context, cognitive and procedural competences were preferred (also, other cross-competences). On the other hand, Argentines preferred the emotional-affective and social aspects (bonds, or competences associated to "knowing how to be"). That is expected if we take into account Argentina's history: a country which received huge hordes of immigrants and integrated them easily. In France, however, training in "knowing how" has a longer tradition and is more internalized by the individuals. As for the rest, they do not expect much from the market. They are aware, since the moment they chose their courses of study, that it would be difficult to reach a solid socio-economic position. Finally, in the field of management/administration, they preferred material aspects (income) and other associated ones (prestige, status, and the hierarchical position which can be achieved by choosing that particular field of study). As regards the training in competences on the part of the university, they looked happier. The interplay between the individuals and educational institutional frameworks appears clear. Valuing competences which are necessary today shows marked differences according to disciplinary area and country.

(2) Professional mobility/professional satisfaction and expectations: It could be observed here that those who got higher in the professional scale since they started their Ph.D. education do not always feel most satisfied. This led us to coin the terms objective and subjective satisfaction (although it may seem repetitive), to which we also added "objective" and "subjective" professional mobility. In fact, not all of them perceive or get a representation of such mobility in the same way, some almost do not mention mobility when dissatisfaction is dominant. This was mainly observed among the doctors in the field of sociology, many of whom hold interesting positions (especially in France). "Feeling" mobility and "feeling satisfied" go beyond promotion or rise. Much would seem to depend on cherished expectations: The more it is expected and the more the day-to-day practice gets apart from the preexisting ideal, the less enjoyable is success, regarding status, and psychological wellbeing. The hypotheses of the Expectancy-Valence Theory are confirmed.

(3) The same could be said of the Theory of Education, understood as consumption or as investment. Significant satisfaction is often observed, for example, among those who teach at university, which does not provide economic benefits in terms of status (it is rather a devalued profession), social prestige, or mobility; i.e., it is not included into the investment dimension, as it happened around the middle of the last century (Becker 1964).

(4) Mobility and satisfaction: These two variables are associated to professionalization (understood as upgrading and updating as regards today's market demands) and identity (understood as the result of a history combined with recognition obtained within a socio-professional context). Difficult mobility in times of quick changes and employment crisis, in addition to the many new conflict aspects that come up in the different worksites, cause many doctors not to get recognition in their companies or the government, being forced to take much inferior jobs than those expected according to their education. Satisfaction, logically, appears as a far-away goal to be conquered. Many seek to change jobs, to get more training in search for other positions, etc. As Goffman (1963) stated, they appeal to "identity strategies" in order to face this problem, which is more obvious in the French group, where the word recognition was most mentioned and given the greatest importance to refer, precisely, to a "shortcoming". Among Argentines, the most mentioned word in relation with macro contexts was "political credibility" to point out, exactly, a lack 
of it, which has been growing since the '90s. This causes anomic behavior, uncertainty, and an almost complete absence of projects of life, which afflicts or weakens personal and professional identity, returning over the meso organizational levels and the macro level. This aspect was so obvious that the INDEC (National Statistics Institute) included discourage as an indicator of quality of life.

(5) The interaction of the three levels-the individual, its immediate context, and the macro social context - appears in an integrating, rich, non-linear play. This interplay, also requires an inter- and trans-disciplinary look if we wish to comprehend and not just explain the "roots" or "reasons" underlying human behaviors.

\section{CONCLUSIONS}

The author's findings beg us to stop thinking in linear terms when dealing with variables that are apparently linked in this way.

Some individuals have little prestige and power without having experienced mobility or ascension, as is the case with teachers, however, they are happy in their profession. Others, on the other hand, who ascended hierarchically (as is the case with many sociologists), do not associate their ascension with subjective achievement. They are not satisfied with their workplace environment or with many companies' or organizations' political alignments. Nor are they happy with education received - despite the fact that having a doctorate is always a plus - and even less so with continuing professionalization or education which is essential for responding to current demands.

Satisfaction is also associated with the academic field chosen and with related expectations. Those choosing to be teachers do not prioritize prestige and power. Their education is understood in terms of "consumption" more than as an "investment", as personal/professional fulfillment of a vocation. On the contrary, those choosing to manage companies who, after having ascended the ranks, find themselves in unfavorable workplace environments with insufficient collective competencies for the job despite mobility, cannot feel satisfied. More mobility does not mean more satisfaction. Values also play a role. And these values relate to an individual at the micro-psychological level, to the organization that he or she is a part of and even to a country's idiosyncrasies. In France, "know-how" is highly valued, having the procedural and cognitive tools to carry out one's work; however, in Argentina-a country which received a significant number of immigrants and did not differentiate based on ethnicity, race, or other characteristics, affective and interpersonal factors are more highly valued when evaluating satisfaction ("know to live").

"Plafond" effects were also observed, influencing possibilities of fulfillment/satisfaction and identity wellbeing. These were more marked in France than in Argentina, a country where $\mathrm{PhD}$ saturation is greater and, consequently, where PhDs frequently have more trouble inserting themselves into and remaining in the workplace. As such, they must rely on identity strategies to "survive" in the system.

In sum, variables which at first appeared were not linear. The interweaving of factors is very rich and as such a true understanding of the phenomenon implies utilizing not only quantitative techniques which measure each variable but also qualitative techniques that allow one to delve into the "reasons" hidden by individuals and organizations. These "reasons" (even when they are not very reasonable), underlie election, self-selection, recruiting, and evaluation behaviors. They reveal the "preferences" and values of individuals inserted into meso organizational and macro national contexts. The three levels interact, generating situations which are, many times, far from generalizations. The author's strategy-macro-meso-micro-macro-emerges as a possible reading of socio-organizational and cultural behaviors in situations that have particular 
characteristics and therefore require pertinent responses.

\section{References}

Aparicio, M. 2005. "Les facteurs psychosociaux et la réussite universitaire et professionnelle" (Psycho-Social Factors and Professional Achievement). 2nd $\mathrm{PhD}$ thesis, Sorbonne, France.

- 2007. "Mobilité et réussite universitaires et professionnelles. Du niveau macro au niveau micro" (Mobility and University and Professional Achievement. From Macro Level to Micro Level). HDR (Education). Université Paris X, Nanterre, France.

—. 2009a. "Les facteurs psychosociaux et la réussite universitaire et professionnelle" (The Psycho-Social Factors and Professional Achievement). Université de Lille 3: ANRT.

—. 2009b. "Trajectoires des docteurs et identités" (PhDs Career Paths and Identities). Award. Marie de Paris, France.

—. 2011. "Les trajectoires des étudiants, un jeu entre les sujets et leurs contextes institutionnels. Acta Europeana Systemica" (Students Career Paths: An Interplay Between the Subjects and Their Institutional Contexts). On Line Journal of the European Union for Systemics (EUS) (December 7, 2011 On Line issue). Vol. 1.

—. 2012. "Trajectoires universitaires/professionnelles et identité" (University Professional Career Paths and Identity). Pp. 195-229 in Formations et professionnalisations: à l'épreuve de la complexité (Training and Professionalization: A Test of Complexity), edited by J. Clénet, Ph. Maubant, and D. Poisson. Paris: L'Harmattan.

- 2014a. "Satisfaction, Professional Mobility and Leadership in Academic-Scientific Organizations." Journal of Health Science 2(3):135-145.

_ 2014b. "Postgraduate Level and Its Impact on Academic Studies and Professional Careers, Social and Job Mobility and Identity. A Study About $\mathrm{PhD}$ Graduates and $\mathrm{PhD}$ Students at UNCuyo, in the Light of a Sui Generis Paradigm." Journal of Educational and Social Research 4(2), Special Issue-April.

—. 2015a. "Towards a Sui Generis Systemic Theory: The Three-Dimensional Spiral of Sense. A Study in Argentina Applied to Identity and Professionalization." (Article 1). Asian Academic Research Journal of Social Sciences \& Humanities 2(7) (December):246-282.

- 2015b. "The Theory of the Three-Dimensional Spiral of Sense: An Application With Special Reference to Identity and Professionalization in Other Disciplinary Areas." (Article 2). Asian Academic Research Journal of Social Sciences \& Humanities 2(7) (December):194-245.

- 2015c. "Identity, Weakening and Professionalization: A Study of Graduate and Postgraduate Students (1987-2002) in the Light of the Three-Dimensional Spiral of Sense Theory." Pp. 131-156 in International Handbook of Professional Identities, edited by A. M. Silva and M. Aparicio. Scientific and Academic Publishing.

_ 2016a. "The Three Dimensional Spiral of Sense: A New Paradigm Systemic Applied a Six Areas Disciplinary and Two Axes: Identity and Professionalization." European Journal of Interdisciplinary Studies Jan.-Apr. 4(1):40-51.

—. 2016b. "Homogenization and Mass Identity vs. Individual Identity. An Analysis at the Light of a New Theory: 'The Three Dimensional Spiral of Sense'." European Journal of Interdisciplinary Studies Jan.-Apr. 4(2):40-49.

—. 2016c. "Resiliency, Professionalization and Identity. A Study in Relation to Achievement at University at the Light of a New Paradigm: The Spiral of Three Dimensional of Sense." European Journal of Interdisciplinary Studies Jan.-Apr. 1(3):126-131.

_. 2016d. "Barriers to Learning, Achievement, Institutional Identities and Professionalization. Barriers to Learning, Achievement, Institutional Identities and Professionalization." European Journal of Social Sciences, Education and Research Jan.-Apr. 6(1):78-87.

—. 2016e. "Professionalization, Insertion, Mobility and Professional Status. A Comparative Analysis in Populations of Doctors." European Journal of Economics and Business Studies September-December 6(1):161-170.

—. 2016f. "Professional Mobility and 'Objective' and 'Subjective' Satisfaction. A Non-linear Analysis From the Theory of the Three-Dimensional Spiral of Sense in Population of Doctors." European Journal of Interdisciplinary Studies September-December 3(1):52-62.

Aparicio, M. and F. Cros. 2015. Trajectoires et identités. Un avenir incertain pour les docteurs (Career Paths and Identities. An Uncertain Future for PhDs)? Paris: L'Harmattan.

Argyris, C. and D. Schön. 1978. Organizational Learning. Cambridge, Massachussets: Harvard University.

- 1996. Theories of Action, Double-Loop Learning and Organizational Learning. Cambridge, Massachussets: Harvard University.

Becker, G. 1964. Human Capital. New York: National Bureau of Economic Research.

Boudon, R. 1973. L'inegalité des chances. La mobilité sociale dans les sociétés industrielles (The Inequality of Opportunities. Social Mobility in Industrial Societies). Paris: 
PUF.

Bourdoncle, R. and L. Demailly, eds. 1998. Les professions de l'éducation et de la formation (The Professions of Education and Training). Paris: Septentrion.

Dubar, C. 2000. La crise des identités (Identity Crisis). Paris: PUF.

Feather, N. and P. Davenport. 1981. "Unemployment and Depressive Effect: A Motivational and Attributional Analysis." Journal of Personality and Social Psychology 41(3):422-436.

García Rodríguez, Y. 1993. Desempleo: Alteraciones psicológicas (Unemployment: Psychological Alterations). Valencia: Promolibro.

Goffman, E. 1963. Stigmates. Les usages sociaux des handicaps (Stigmatized. Social Uses of Handicaps). Paris: Minuit.

Lévy-Garboua, L. 1976. "Les demandes de l'étudiant ou les contradictions de l'université de masse" (The Student's Demands or the Contradictions of Mass Universities). $R$. Franç Soc. 17(1):53-80.

Mingat A. and J. Rasera. 1981. "Enquête longitudinale 3. Après la première année d'études. Réorientation, réussite, scolarité" (Longitudinal Survey 3. After the Freshman Year. Reorientation, Achievement, School Years). Dijon, University de Dijon, IREDU.

Ozga, J. and M. Lawn. 1981. Teachers Professionalism and Class: A Study on Organized Teachers. London: Falmer Press.

Silva, A. M. and M. Aparicio (Comp.). 2015. International Handbook About Professional Identities. USA: Publishing Editors.

\section{Bio}

Miriam Aparicio, Ph.D. in Education and Psychology, professor of Social Psychology in the School of Philosophy and Literature, National University of Cuyo, Mendoza, Argentina, main researcher of National Council of Scientific Research (CONICET, Argentina); research field: social and human sciences. 